\title{
BIM 技术在建筑工程施工管理中的应用
}

\author{
王功祯 \\ 青岛荣安装饰工程有限公司，山东青岛 266000
}

[摘要]近年来, 在多方面利好因素的影响下, 使得我国社会经济水平得到了显著的提升, 从而促进了民众生活水平的提升, 在这种形势下人们对生活环境的需求也在逐渐的提升。建筑工程涉及到的施工工作量较为巨大，具有非常明显的复杂性，并 且工程整体成本较大, 施工持续较长, 施工人员人数众多, 这些因素都对工程施工管理工作的实施造成了诸多的阻碍。所以, 为了从根本上对建筑工程施工质量加以保证, 那么最为重要的就是需要从不同的角度入手来提升施工管理工作的力度, 提高 建筑工程能施工管理工作整体水平。将 BIM 技术引用到建筑工程施工管理工作之中, 对于保证各项施工建设工作的有序开展 能够起到积极的推动作用, 确保建筑工程施工安全和质量。

[关键词]BIM 技术; 建筑工程; 施工管理; 应用

DOI：10.33142/sca.v3i4.2168 中图分类号: TU17;TU741

文献标识码：A

\section{Application of BIM Technology in Construction Management of Building Engineering}

WANG Gongzhen

Qingdao Rong'an Decoration Engineering Co., Ltd., Qingdao, Shandong, 266000, China

\begin{abstract}
In recent years, under the influence of many favorable factors, China's social and economic level has been significantly improved, thus promoting the improvement of people's living standards. In this situation, people's demand for living environment is also gradually improving. The construction work involved in the construction project is relatively huge, with a very obvious complexity, and the overall cost of the project is large, the construction continues for a long time, and the number of construction personnel is large, these factors have caused many obstacles to the implementation of the project construction management work. Therefore, in order to fundamentally guarantee the construction quality of construction projects, the most important thing is to improve the strength of construction management work from different angles and improve the overall level of construction management work. The application of BIM Technology in the construction management of construction engineering can play a positive role in ensuring the orderly development of various construction work, and ensure the safety and quality of construction engineering.
\end{abstract}

Keywords: BIM technology; construction engineering; construction management; application

\section{引言}

与以往的各类建筑施工技术进行对比来说, BIM 技术具有非常明显的优越性, 无论是在工作效率还是在资源利用方 面, 都能够发挥出积极地影响作用。所以, BIM 技术的实践运用, 能够为建筑工程施工工作创造良好的施工环境, 为施 工管理工作的有序开展给予辅助。

\section{BIM 技术内涵}

BIM 技术是社会科学技术发展的产物, 是当前最前沿的信息化技术, 其实质是结合建筑工程项目各项信息数据来实 施管理工作的重要方式。实施基础信息仿真模拟的时候, 三维建筑模型的创建可以确保建筑信息工程的真实性, 从而 对各项建筑施工工作进行全程控制。在实施信息化管控工作的过程中, BIM 技术的运用实用性较强, 对于建筑工程施工 过程中的各类控制要点以及各方面情况需要实施可视化分析工作, 这样才可以从根本上保证效果图达到立体化的效果。 BIM 技术适合使用的范围较为广泛, 在实践利用这项技术的时候, 可以保证获得立体化的效果, 综合各方面变量因素, 针对工程施工管理工作进行适当的调整，从而将管理工作进行优化完善，保证管理工作整体效果。

\section{$2 \mathrm{BIM}$ 技术的特点}

2. 1 协调性

在实际开展建筑工程施工工作的时候, 无论是施工单位还是相关设计机构之间都存在一定的关联，一旦建筑工程 项目在是过程中遇到任何的问题, 需要各个部门之间通力协作加以解决, 判断诱发问题的根源, 利用有效的方式方法 来加以解决。如果在上述工作中, 各个部门之间的合作不顺畅, 工作交接效果较差, 最终就会造成工程工期的延长, 并且会产生大量的损失。BIM 技术所具有的良好的调节性, 能够确保相关工作人员在进行工作交接的时候, 能够结合三 维工程结构模型来对各项工作进行合理的分配。BIM 技术可以借助计算机技术针对所有的信息数据进行综合分析, 从而 可以对各个部门之间所存在的技术问题以及差异加以解决, 针对建筑工程各项工作进行整体安排和规划, 保证项目工 
程各项工作能够有序的开展。

\section{2 可视性}

建筑工程项目具有较强的系统性和综合性, 涉及到的工程量较为巨大, 所以要想保证各项工作的有序开展, 要保 证管理工作的整体效率和质量。就以往老旧的施工管理模式来看, 具有非常明显的局限性, 在实际落实管理工作的时 候, 如果没有较强的直观感、体验感, 那么是无法将施工管理工作的作用充分的发挥出来的。但是将 BIM 技术加以切 实的引用, 能够有效的对施工管理工作的落实给予良好的协助。BIM 技术其实质就是借助计算机为介质, 利用专门的软 件来实施管理, 将建筑施工管理工作牵涉到的所有的信息数据进行统一分析管理, 利用所有的信息数据创设施工图, 管理工作人员利用计算机能够对各项建筑施工工作进行可视化管理。

\section{3 模拟化}

BIM 技术最为突出的优越性就是能够对建筑工程施工各个细节进行模拟, 涉及到工程所处地区地质结构的模拟, 工 程施工过程中各类危险情况的模拟, 工程后期可能遇到的问题的模拟等等, 综合模拟结果针对工作进行合理的安排, 尽可能的避免各类安全隐患情况的发生, 提升工作的效率, 保证各项建筑工程施工工作能够按部就班的进行。 ${ }^{[2]}$

\section{BIM 技术在建筑工程施工管理中具体应用}

\section{1 将 BIM 技术应用到计算管理过程中}

因为 BIM 技术拥有较强的功能性, 并且牵涉到的建筑工程影响因素较多, 所以在将 BIM 技术切实的引用到建筑工 程管理工作之中, 能够有效的提高管理工作的效率。首先, 因为 BIM 技术在实践运用的过程中能够具有良好的计算能 力, 从而保证计算结果的准确性, 诸如: 在针对建筑工程施工过程中各项原材料进行采买之前, 原材料的采买数量需 要充分结合相关行政机构制定的规范标准进行计算, 如果单纯的利用人工进行计算, 不但会导致管理工作人员工作量 的增加, 并且也会损害到计算结果的准确性。而将 BIM 技术引用到模拟系统之中, 系统可以结合编程指令来进行计算, 并且计算的结果具有良好的准确性, 结合计算结果采购人员可以对材料采购, 避免发生材料浪费的情况, BIM 技术具有 良好的科技性和专业性。

\section{2 BIM 技术的应用能够将施工图纸进一步深化完善}

在开始建筑工程施工工作的初期, 切实的运用 BIM 技术能够对招标方案以及施工图纸进行优化和完善, 保证设计 图纸能够具有良好的可行性。借助 BIM 技术可以对工程涉及到的各个管道线路结构利用三位模型的形式加以呈现, 从 而有效的解决了老旧模式的二维设计图所具有的局限性的问题。在二维设计图中, 只是将各个分支平面系统的管道线 路进行单纯的叠加, 无法准确的判断各个分支结构之间所存在的碰撞问题。而运用 BIM 技术可以将所有的设计放在一 个三维模型之中, 模型结构都需要依据真实尺寸按照一定的比例进行设计, 针对各个结构进行协调优化, 针对碰撞点 加以全面检测, 这样才可以准确的判断隐藏的风险, 从而对设计加以优化。

\section{3 施工进度计划制定}

在 BIM 技术的辅助下, 能够提升各项施工工作的效率, 综合数据信息来获得建筑各项信息资料, 综合各方面实际 情况来对各类资源进行合理的分配和高效的利用。结合信息数据来编制切实可行的工程施工计划，将施工技术与 BIM 平台内的资源进行融合, 创设完善的信息模型, 增强模拟效率, 避免施工过程中出现任何的失误。其次, 针对从多个 角度对工程施工进度进行全面的掌控, 对于施工人员的各项工作给予详细的安排和划分, 从而确保各项施工工作的有 序开展, 如果遇到任何的突发情况, 要运用有效的方式方法来加以解决, 保证施工的进度。

\section{4 BIM 技术在建筑工程质量管理中应用}

在针对建筑工程施工工作进行管理的时候, 工程质量管理工作可以说是最为重要的一项内容, 这项工作的效率往 往会与民众的生活质量存在密切的关联。现如今就我国建筑工程质量管理工作实际情况来说, 整体水平还处在较低的 状态, 其中还存在诸多的问题需要我们进一步的加以解决。而科技的发展有效的推动了 BIM 技术整体水平的提升, 管 理工作人员可以利用这项技术针对施工材料、施工人员以及机械设备进行全面的管控, 从而从根本上提升施工的效率, 保证建筑工程施工的质量。 ${ }^{[4]}$

\section{结束语}

综合以上阐述我们总结出, 将 BIM 技术切实的运用到建筑工程管理工作之中, 能够显著的提升管理工作整体水平, 提高各类资源利用效率，避免发生资源浪费的情况。

[参考文献]

[1]王齐奎. BIM 技术在建筑工程施工管理中的应用探索 [J]. 城市建筑, 2019, 16 (27) : 132-134.

[2] 赵增水. BIM 技术在建筑工程施工管理中的应用探索 [J]. 居业, 2018, 6 (12) : 16-17.

[3] 李燕. BIM 技术在建筑工程施工中的应用策略 [J]. 科学技术创新, 2018, 9 (35) : 105-106.

[4]卢江山. BIM 技术在建筑工程施工管理中的应用探讨 [J]. 四川水泥, 2018,8 (12): 212 .

作者简介: 王功祯 $\left(1988,10^{-}\right)$, 男, 西南科技大学, 土木工程专业, 当前就职单位: 青岛荣安装饰工程有限公司, 职 务: 项目经理。 